time when crystal growth was more of an art than a science belongs definitely to the past.

As for all similar conferences the quality of the papers is somewhat variable, but by and large one can say that the material presented covers, on the whole adequately, the present state of the art. The book is therefore a must for every laboratory involved in growing crystals.

The publishers have done an excellent job; not only was the book published in a very short time but also the presentation is of the same high quality as that of the Journal of Crystal Growth published by the same company. In particular the reproduction of the numerous photographs is excellent.

\section{S. Amelinckx}

S.C.K.

Mol

Belgium

The American Mineralogical Journal. Archibald Bruce, M.D. Contributions to the History of Geology. Vol. 1. Edited by George W. White. Pp. xvii + 270. New York: Hafner, 1968. Price U.S. \$18.00.

This facsimile of the 1814 edition of the short-lived American Mineralogical Journal will provide interesting reading for historians of geology and mineralogy. The simple, narrative style of many of the contributors gives us delightful accounts of pioneers of American geology in the early nineteenth century, at the same time preserving the thrill of their discoveries. This aspect of the journal should make Volume I of this series of interest not only to professional historians of the natural sciences, but to many amateur collectors on both sides of the Atlantic.

Consultation of the list of contributors to the journal reveals notable geologists and mineralogists from Europe and America. As Professor John C. Greene points out in his Introduction, Archibald Bruce had the opportunity of making the acquaintance of many leading mineralogists during a five-year reriod of study and travel. Count de Bournon, Charles Francis Greville, Abbé René Just Haüy and Heinrich Struve were among those notable figures whom he was privileged to encounter. The first publication of the Journal in 1810 (January) includes a comprehensive list of 'Geologocal Inquiries' as proposed by the London Geological Society. The varied professional status of the contributors to the Journal certainly confirmed Bruce's intentions to enlist the services of 'the miner, the quarrier, the surveyor, the engineer, the collier, the iron master and even the traveller', to assist in the making of geological observations.

Much of the content of the Journal is devoted to the search for and study of minerals of economic importance - coal, iron, lead, copper. Number 3 of the Journal includes a lengthy extract by Dr. James Millar of Edinburgh, entitled Of the Indications of Coal and Methods of Searching for It. The reason given for this insertion is "the rising price of fuel due to the interruption of our supplies of coal from Great Britain due to the present state of political affairs"! A similar reference to the importation of bar-iron from England to the United States, 1810, serves, with many other such examples, to illustrate the reversal of the economic interpendence of the two countries in the intervening century and a half.
Contributions under the heading 'Intelligence' comprise many news items which will be read, even today, with considerable interest. The eruption of Vesuvius in September 1810 is graphically reported. Meteoric falls in France and Russia, 1810 and 1811 , are catalogued with accuracy and William Meade M.D. gives us such an enthusiastic account of his discoveries concerning 'Elastic Marble' that one's fingers itch to repeat the experiment.

This edition of the Journal is ably supported by Professor John C. Greene's biographical account of Archibald Bruce, whose premature death at the age of forty-one cannot but be lamented by anyone who reads of his valiant attempts to establish an American Mineralogical Journal.

Sister luigi Farrell F. C. J.

Science Department

Sedgley Park College of Education

Prestwich

Manchester

England

La Fatigue des Métaux. By R. Cazaud. Fifth edition, revised by C. Pomey, R. Rabbe and $\mathrm{Ch}$. JansSen. Pp. xviii + 622. Paris: Dunod, 1969. Price 128F.

Fatigue breakdown can occur in any highly stressed machine where the imposed stresses are of a periodic nature.

The first edition of this book was published in 1937 and subsequent editions in 1943, 1948 and 1959. This latest edition is right up to date and incorporates the results of the latest theoretical and experimental work carried out all over the world. This work will be of interest to metallurgists and engineers and, indeed, to anyone involved in the design, construction or use of machinery.

The illustrations and general presentation are of the usual high Dunod standard.

Department of Physics

University of York

Heslington

York

England

Optical crystallography. Fourth edition. By ERNEST E. Wahlstrom. Pp. 489. London: Wiyle, 1969. Price $132 \mathrm{~s}$.

This is the fourth edition of a book first published in 1943. It deals in a systematic and exhaustive way with all aspects of the behaviour of light when it passes through transparent materials.

Initial chapters (about 200 pages in all) are devoted to the elementary basic concepts of nptial crystallography crystal morphology, the nature of light, the optics of isotropic materials, measurement of refractive index, polarized light and interference and other phenomena concerned with the composition and resolution of light waves.

The treatment is for the most part descriptive and the mathematics is kept to a minimum. Since the diagrams are 
numerous and of a good standard the basic concepts are put over quite well. However in his preface the author states that, quite deliberately, his material is a collection of theory and recipes and sometimes this reviewer felt that the theory was a little underplayed. For example, Miller indices are introduced without any reference to the underlying reasons for their existence and a reader fresh to the subject might well wonder at the good fortune that made them such small integers.

The next 160 pages give a very complete and highly satisfactory explanation of the optical properties of uniaxial and biaxial crystals and their behaviour under the orthoscope and conoscope. Once again the quantity and quality of the diagrams help greatly to clarify the subject matter.

Final chapters are devoted to optically active crystals, the study of crystals mounted on stage goniometers and, finally, a detailed procedure for the systematic microscopic examination of transparent materials.

This book is highly recommended to all crystallographers. Even the least 'optically aware' crystallographer would do well to have it handy as a work of reference.

Department of Physics

M. M. WOOLFSON

University of York

Heslington

York

England

Einf ührung in die Kristallphysik. By W. KLEBER, K. MEYER and W. SCHOENBORN. Pp. 209. Berlin: Akademie-Verlag, 1968. Price (soft cover) DM 17.

This book is written as an introduction to crystal physics for undergraduate and graduate students majoring in physics, chemistry and mineralogy.

The first chapter by Schoenborn on Elemente der Kristallsymmetrie deals with crystal classes including those of the magnetic type. In the second chapter Phänomenologische Darstellung der Kristalleigenschaften the same author, after a brief mathematical introduction, discusses certain crystal properties by means of tensors. This includes, for example, pyroelectricity, pyromagnetism, conductivities, optical activity, double refraction, piezoelectricity, elasticity, etc. Chapter 1 appears too brief and superficial but the second chapter gives a good discussion of the mentioned physical properties.

Kleber has written Chapter 3 Gitterphysikalische Eigenschaften. He discusses crystal bonding, potential and vibrations, and elastic, magnetic dielectric, and optical properties. This is a very brief and rather unproblematic account of the phenomena.

Finally, Meyer gives in Chapter 4, Realstruktur und einige physikalische Eigenschaften, a good and brief description of the geometry of crystal defects, their detection and some physical properties due to defects.

Although there is a strong need for a short textbook on crystal physics, I am not sure this book fulfils this purpose, particularly since the material included is not up-to-date.
Also, since this book is very brief, it should include a more detailed reference section.

Polytechnic Institute of Brooklyn

H. WAGENFELD

333 Jay Street

Brooklyn

New York 11201

U.S.A.

Crystals and their structures. By ARTHUR P.CRACKNELl. Pp. ix +231 . Oxford: Pergamon Press, 1969. Price (hard cover) $45 s, \$ 7.00$, (sofi cover) $35 s, \$ 5.50$.

This book deals, at an elementary level and in a descriptive way, with the properties and structures of crystalline and near-crystalline materials.

It is intended as reading matter for advanced sixth-form pupils studying physics or chemistry or as general background reading for first-year undergraduates.

The first two chapters, comprising one third of the book, are concerned with the symmetry of crystals, point groups, Bravais lattices and space groups. The treatment is quite sound but, in the reviewer's opinion, some topics, e.g. symmorphic space groups and $d$-glide planes, should have been excluded completely. They were dealt with so scantily that they could not easily be understood and their inclusion added nothing to the overall understanding of the material.

A chapter on the internal structure of crystals gives a brief account of each of the three main types of diffraction experiment, with X-rays, electrons and neutrons and also of electron microscopy. There are useful descriptions of electrostatic lenses and of how a magnetic structure can be elucidated with neutrons. A very important point, not made at all, is that structural information may be difficult to obtain from diffracted data, which is, after all, one of the basic features of structural crystallography.

The next chapter deals with the forces which bind crystals together, ionic and covalent bonding forces and van der Waals forces. The section of this chapter which deals with energy-band theory is done quite well and should be useful at the introductory undergraduate level.

The book concludes with three short chapters, one dealing with defects, dislocations and non-crystalline materials and the final two with coloured symmetry and with elementary group theory.

A useful appendix includes instructions for making cardboard models (octahedron, rhombic dodecahedron, etc.) and gives some tips for crystal growing.

The book is interspersed with numerous examples, some fairly difficult, whose usefulness would have been enhanced had solutions, perhaps even worked solutions, been provided.

To summarize - some flaws but a good book on the whole. It can be recommended to that class of readers for which it is intended.

Department of Physics

M.M.WOOLFSON

University of York

Heslington

York

England 